\title{
Bankalardaki Bölümsel Raporlama Uygulamalarının TFRS 8 Faaliyet Bölümleri Standardı Çerçevesinde İncelenmesi: Bir Uygulama Önerisi
}

\author{
Serkan ÖZDEMIR *
}

\begin{abstract}
ÖZET
Dünya ticaret hacminin büyümesi ile beraber birden çok alanda faaliyet göstermeye başlayan şirketlerde, konsolide edilen finansal tablolardan elde edilen finansal bilgiler, kullanicllara detaylarl gösterme konusunda yetersiz kalmaya başlamıştır. Bu sebeplerle son zamanlarda önemini arttıran bölümsel raporlama faaliyetleri Türkiye'de TFRS 8 Faaliyet Bölümleri Standardı şartları doğrultusunda uygulanmaktadır. TFRS 8 Standardı bölümsel raporlamada bir şablon önermemekte, şirketleri bölüm yapılarını oluşturmada ve bölümlendirilecek finansal bilgilerin seçiminde serbest birakmaktadır. Bu durum standardın temelini oluşturan "Yönetim Yaklaşımı"nın bir sonucudur. Türkiye'de bankacılık sektörü, kendine has işleyiş kuralları ile benzer ticari faaliyetlerin gerçekleştirildiği bir sektördür. Fakat sektördeki bölümsel raporlama uygulamalarında, yukarıda belirtilen sebeplerden dolayı bir uygulama birliği sağlanamamıştır. Bu durum bölümsel raporlardaki finansal bilgilerin karşılaştırılmasını ve analizini güçleştirmektedir. Yapılan uygulama çalışması ile, bankalardaki farklı bölümsel raporlama uygulamalarını ortak bir paydada birleştiren, bir bölümsel raporlama önerisi ortaya konulmuştur. Böylece sektörde konunun tartışmaya açlarak, bölümsel raporlamada temelde bir uygulama birliği să̆lanması hususunda farkındalık yaratılması hedeflenmiştir.
\end{abstract}

Anahtar Kelimeler: Bankalar, Bölümsel Raporlama, TFRS 8.

JEL Sınıflandırması: M41, M40.

\begin{abstract}
Analyzing The Segment Reporting Practices Within The Scope Of The TFRS 8 Operating Segments Standart: An Application Proposal

\section{ABSTRACT}

In the companies that started to operate in multiple fields upon the growth of the global trade volume, the financial data obtained from consolidated financial statements are insufficient to show the details to the users. Therefore, the segment reporting practices which have been very important recently are conducted in accordance with the terms of TFRS 8 Operating Segments Standart in Turkey. TFRS 8 standard does not offer a template in segment reporting, but lets the companies free to establish the segment structures and to choose the financial data to be segmented. This is the consequence of the "Management Approach" which underlies the standard. Banking sector in Turkey is the sector where similar business operations are conducted with its own unique mechanism. However, there is not any application unity in segment reporting practices in the sector due to the above-mentioned reasons. This complicates the comparison and analysis of the financial data in segment reporting. With the application study, a segment reporting proposal, which combines different segment reporting practices in banks on a common ground, was submitted. Thus, the aim was to create an awareness of maintaining an application unity in principle in segment reporting by bringing the issue forward in the sector.
\end{abstract}

Keywords: Banks, Segment Reporting, IFRS 8.

Jel Classification: M41, M40.

\footnotetext{
* Yrd.Doç.Dr. Serkan Özdemir, Pamukkale Üniversitesi, Buldan Meslek Yüksekokulu, sozdemir@pau.edu.tr.
} 


\section{GíRiş}

Bankalar dünya ticaretinde önemli bir yere sahip işletmelerdir. Büyüyen dünya ticaret hacmi ve küreselleşme bankalara da farklı faaliyet alanlarında ve ülkelerde çalışma imkânları sunmuştur. $\mathrm{Bu}$ sebeple birçok alanda ve ülkede faaliyet gösteren bankaların yönetilmesi ve performans analizlerinin yapılarak geleceğe dönük kararların alınabilmesi gün geçtikçe zorlaşmaktadır. Bölümsel raporlama bu zorlukları bir nebze ortadan kaldırarak, yanlış yönetim kararlarının alınması riskini azaltan bir uygulamadır. Ayrıca kârlılık oranları, büyüme firsatları ve riskler bir faaliyetten diğerine, bir coğrafyadan diğerine önemli oranda değişiklikler gösterebilmektedir. Bundan dolayı farklı faaliyet alanlarında veya farklı coğrafyalarda faaliyet gösteren bankalar, bir bütün olarak işletmeyi, faaliyet gösterdiği ekonomik çevreyi ve bankanın gelişim durumunu anlamak için, bölümleri hakkında finansal bilgilere de ihtiyaç duyarlar (Elitaş, 2012: 124).

Konsolide finansal tablolar bölümlerin kârlılıklarını, nakit akımına katkılarını ve büyüme kapasitelerini gizledikleri için, bazı durumlarda bölümler hakkında yanlış kararlar alınmasına sebep olabilmektedir. Bu sebeple bölüm bilgileri olmadan hem yatırımcı, hem işletme ortağı hem de yönetici gözüyle işletmenin geleceği ile ilgili doğru kararlar verebilmek zorlaşabilmektedir (Benjamin vd., 2010: 33).

Konsolide finansal tabloların bu dezavantajını bir nebze ortadan kaldırmak amacıyla oluşturulan UMS 14 Bölümlere Göre Raporlama Standardı(UMS 14) ve SFAS 131 Bağlantılı Bilgi ve Kuralların Bölümsel İçeriği Hakkında Kamuoyu Bilgilendirme Standardı (SFAS 131), Uluslararası Muhasebe Standartları Kurulu(International Accounting Standards BoardIASB) tarafından tek bir bölümsel raporlama dili oluşturabilmek amacıyla UFRS 8 Faaliyet Bölümleri Standardı(UFRS 8)'nda birleştirilmiştir.

IASB'ın UMS 14 standardını yürürlükten kaldırarak, yerine 1 Ocak 2009'dan itibaren uygulanacak UFRS 8 standardını yayınlaması, TMSK'nın da bu konuda yeni bir düzenleme yapmasını gerekli kılmıştır. Bu çerçevede Türkiye Muhasebe Standartları Kurulu (TMSK), UFRS 8 standardını Türkçeleştirerek, TFRS 8 Faaliyet Bölümleri Standardı(TFRS 8) olarak 15.07.2007 tarihli ve 26583 nolu Resmi Gazete'de yayınlamıştır. TFRS 8 standardı, 31.12.2008 tarihinden sonra başlayan hesap dönemlerinde uygulanmak üzere yürürlüğe girmiştir. TFRS 8 Standardının uygulanmasıyla TMS 14 Bölümlere Göre Raporlama(TMS 14) standardı yürürlükten kaldırılmıştır.

Çalışmaya konu olan Borsa İstanbul'da işlem gören bankalar, 01.01.2009'dan günümüze bölümsel raporlama faaliyetlerini TFRS 8 standardı şartlarına uygun olarak gerçekleştirmektedirler.

\section{2. ÍLGILİ LITERATÜR}

Yapılan detaylı literatür incelemesinde bankalarda bölümsel raporlama uygulamaları ile ilgili geçmişte yapılmış üç çalışmanın bulunduğu tespit edilmiştir. 
Link (2003) tarafından Amerika'da faaliyet gösteren en büyük sekiz bankanın bölümsel raporlarının incelenmesi sonucu çeşitli sonuçlara ulaşılmıştır. SFAS 131 standardının uygulanması ile kamuoyuna açıklanan bölüm bilgi miktarlarında artış sağlandığı tespit edilmiştir. Fakat bu artışa rağmen bankaların bölümsel raporlarının karşılaştırılabilirliğinde bir ilerleme sağlanamamıştır. Bu durumun, SFAS 131 standardının temelini oluşturan "Yönetim Yaklaşımı" ile, her bankanın farklı yönetim yaklaşımları ve organizasyon yapılarından dolayı kendine özgü bölümsel raporlar düzenlemesinden kaynaklandığı belirlenmiştir.

Birt, Kend ve Xian (2007) tarafından yapılan çalışmada, UFRS 8 standardının Avustralya'da faaliyet gösteren bankaların bölümsel raporlarına yapmış olduğu etkiler araştırılmıştır. UFRS 8 standardının uygulanması ile bankacılık sektöründe kamuoyuna açıklanan bölümsel bilgi miktarında ve kalitesinde artış sağlandığı tespit edilmiştir. Ayrıca bölümsel raporların daha anlaşılır hale geldikleri belirlenmiştir. $\mathrm{Bu}$ değişimlerin, finansal tablo kullanıcılarının bankalar hakkında verecekleri kararların doğruluk oranını da arttıracağı öngörülmektedir.

Elitaş vd. (2012) tarafından TFRS 8 standardına geçişin Türkiye'de faaliyet gösteren bankaların bölümsel raporlama uygulamalarında yarattığı etkilerin incelendiğin bir diğer çalışmada, dört farklı sonuca ulaşılmıştır. (1) Kamuoyuna açıklanan toplam bölüm ve bölümsel bilgi miktarında artış sağlanmıştır. (2) Kamuoyuna açıklanan toplam bölüm miktarında artış sağlanmıştır. (3) Yönetim yaklaşımının banka yönetimlerine sağladığı serbestlik, her bankanın başka bir formatta bölümsel raporlama düzenlemesine sebep olmaktadır. Fakat bu durum bölümsel raporların karşılaştırılabilme imkânını azaltmaktadır. (4) Kamuoyuna rakiplerine göre daha çok bölümsel bilgi açıklayan bankalar, diğer faktörlerin sabit kaldığı bir ortamda uzun vadede kârlılık ve sermaye maliyeti açısından daha avantajlı hale gelecektir.

\section{BANKALARDA BÖLÜMSEL RAPORLAMA UYGULAMALARI}

Birçok alanda faaliyet gösteren bankaların yönetilmesi ve performans analizlerinin yapılarak geleceğe dönük kararların alınabilmesi gün geçtikçe zorlaşmaktadır. Ayrıca kârlılık oranları, büyüme firsatları ve riskler bir faaliyetten diğerine önemli derecede değişiklikler gösterebilmektedir. Bundan dolayı farklı alanlarda faaliyet gösteren bankalar, faaliyet gösterdikleri ekonomik çevreyi ve bankanın gelişim durumunu anlamak için, bölümleri hakkında finansal bilgileri de sunmalıdırlar (Elitaş vd. 2012: 132).

Bölümsel raporlamanın temel kurallarını belirleyen TFRS 8 standardının temel amacı, standardın uygulanması sonucu sunulacak bölümsel raporlama bilgilerinin, finansal tablo kullanıcılarına şirketler hakkında en doğru finansal sonuçları sunması ve bunun sonucunda şirket faaliyetleri konusunda doğru kararlar alınmasını sağlamaktadır. Standardın uygulamaya başlandığı 2009 yılından itibaren, literatür çalışmasında ifade edildiği gibi, bankaların 
bölümsel raporlarında açıkladıkları bölüm sayılarında ve finansal bilgi miktarlarında artış sağlandığı görülmektedir.

Yapılan bu çalışmada öncelikle TFRS 8 Faaliyet Bölümleri standardının bankalardaki bölümsel raporlamada yarattığı son değişiklikler tespit edilmeye çalışılmıştır. Veriler 14 Aralık 2014 tarihinde Borsa İstanbul'da işlem gören 16 bankanın, 31 Aralık 2008, 31 Aralık 2009, 31 Aralık 2010, 31 Aralık 2011, 31 Aralık 2012 ve 31 Aralık 2013 tarihli Kamuoyu Aydınlatma Platformu internet sitesinden elde edilen finansal tabloları ve dipnotlarına uygulanacak içerik analizi ile elde edilmiştir.

Çalışma kapsamında incelenen Aralık-2014 tarihli Borsa İstanbul'da işlem gören bankalar Tablo 1'de belirtilmiştir. 2014 yılında faaliyete geçen Odeabank, karşılaştırma imkânı sağlamadığından araştırmaya dahil edilmemiştir.

Tablo 1: Aralık-2014 Tarihli Borsa İstanbul'da İşlem Gören Bankalar

\begin{tabular}{|c|l|c|l|}
\hline $\mathbf{1}$ & AKBANK & $\mathbf{9}$ & T. KALKINMA BANKASI \\
\hline $\mathbf{2}$ & ALBARAKA TÜRK & $\mathbf{1 0}$ & T. İş BANKASI \\
\hline $\mathbf{3}$ & ALTERNATİF BANK & $\mathbf{1 1}$ & ŞEKERBANK \\
\hline $\mathbf{4}$ & ASYA KATILIM BANKASI & $\mathbf{1 2}$ & T.EKONOMİ BANKASI \\
\hline $\mathbf{5}$ & DENİZBANK & $\mathbf{1 3}$ & TEKSTİLBANK \\
\hline $\mathbf{6}$ & FİNANSBANK & $\mathbf{1 4}$ & T.S.K.B. \\
\hline $\mathbf{7}$ & T. GARANTİ BANKASI & $\mathbf{1 5}$ & T. VAKIFLAR BANKASI \\
\hline $\mathbf{8}$ & T. HALK BANKASI & $\mathbf{1 6}$ & YAPI VE KREDİ BANKASI \\
\hline
\end{tabular}

Bankaların 2008-2009-2010-2011-2012-2013 yıllarına ait bölümsel raporları detaylı bir şekilde incelendiğinde tespit edilen üç farklı durum Tablo 2'de belirtilmiştir.

Tablo 2: Bankalarda Bölümsel Raporlama İle İlgili Tespit Edilen Diğer Durumlar

\begin{tabular}{|c|c|c|}
\hline $\begin{array}{c}\text { TFRS 8 Standardı İle } \\
\text { Açıklanan Finansal Bilgi } \\
\text { Miktarını Arttıran Bankalar }\end{array}$ & $\begin{array}{c}\text { TFRS 8 Standardı İle } \\
\text { Faaliyet Bölümleri Sayısını } \\
\text { Arttıran Bankalar }\end{array}$ & $\begin{array}{c}\text { TFRS 8'in Bölümsel } \\
\text { Raporlamada Değişiklik } \\
\text { Yaratmadığı Bankalar }\end{array}$ \\
\hline T.EKONOMİ & T.EKONOMİ & ALBARAKA \\
\hline T. KALKINMA & T. KALKINMA & ASYA KATILIM \\
\hline DENIZBANK & DENIZBANK & FİNANSBANK \\
\hline YAPI VE KREDİ & YAPI VE KREDİ & T. GARANTİ \\
\hline ALTERNATIF & ŞEKERBANK & AKBANK \\
\hline T.S.K.B. & & T. İŞ BANKASI \\
\hline T. VAKIFLAR & & TEKSTILBANK \\
\hline & & T. HALK \\
\hline
\end{tabular}


TFRS 8 standardı ile ortaya çıkan en büyük beklenti, şirketlerin bölümsel raporlarında açıklayacağı faaliyet bölüm sayılarında ve finnansal bilgi miktarlarında artış sağlanmasıdır. Yapılan incelemede yukarıda ismi geçen yedi bankada açıklanan finansal bilgi miktarında artış tespit edilmiştir. Ayrıca yukarıda ismi geçen beş bankada açıklanan faaliyet bölüm sayısında artış belirlenmiştir.

Standardın yeni şartları ile, bankaların bölümsel raporlarında değişiklikler yaratması hedeflenmiştir. Fakat yapılan incelemelerde TFRS 8 standardının, yukarıda isimleri bulunan sekiz bankanın bölümsel raporlarında herhangi bir değişiklik yaratmadığı belirlenmiştir.

Bankaların 2013 yıllarına ait bölümsel raporlarında açıklanan finansal bilgi miktarları Tablo 3'de ve aynı yıla ait faaliyet bölümleri yapıları da Tablo 4'de belirtilmiştir.

Tablo 3: Bankaların 2013 Yılında Bölümsel Raporlarında Açıklanan Bilgi Miktarı

\begin{tabular}{|c|c|c|}
\hline \multirow[b]{2}{*}{ BANKA ADI } & \multicolumn{2}{|c|}{ AÇIKLANAN BÖLÜMSEL BİLGİ ADEDI } \\
\hline & $\begin{array}{c}\text { Finansal Durum } \\
\text { Tablosu }\end{array}$ & Gelir Tablosu \\
\hline AKBANK & 9 & 7 \\
\hline ALBARAKA & 2 & 6 \\
\hline ALTERNATIF & 4 & 10 \\
\hline ASYA KAT. & 3 & 6 \\
\hline DENIZBANK & 8 & 9 \\
\hline FİNANSBANK & 11 & 10 \\
\hline T. GARANTI & 11 & 8 \\
\hline T. HALKBANK & 20 & 21 \\
\hline T. KALKINMA & 16 & 24 \\
\hline T. İŞ BANKASI & 15 & 23 \\
\hline ŞEKERBANK & 2 & 9 \\
\hline T.EKONOMI & 6 & 9 \\
\hline TEKSTİLBANK & 6 & 10 \\
\hline T.S.K.B. & 6 & 7 \\
\hline T. VAKIFLAR & 16 & 23 \\
\hline YAPI VE KREDİ & 6 & 8 \\
\hline
\end{tabular}


Tablo 4: Bankaların 2013 Yılına Ait Bölümsel Raporlama Yapıları

\begin{tabular}{|c|c|c|c|c|c|c|}
\hline BANKA ADI & \multicolumn{6}{|c|}{ FAALIYYET BÖLÜMLERİ YAPISI } \\
\hline AKBANK & Bireysel & Kurumsal/KOBİ & Hazine & Özel & Uluslararası & Diğer \\
\hline ALBARAKA & Bireysel & Ticari/Kurumsal & Hazine & Dağıtılamayan & & \\
\hline ALTERNATÍF & Kurumsal/Perakende & Yatırım & Diğer & & & \\
\hline DENIZZBANK & Kurumsal & Ticari/Kamu & KOBİ/Tarım & Bireysel & Hazine/Yatırım & \\
\hline FİNANSBANK & Perakende & Kurumsal/Ticari & Hazine/Gen Müd. & & & \\
\hline T. GARANTİ & Bireysel & Kurumsal & Yatırım & Diğger & & \\
\hline T. HALK & Kurumsal & Ticari & Karma & Hazine/Yatırım & & \\
\hline T. KALKINMA & Hazine & Yatırım & Dağıtılamayan & & & \\
\hline ŞEKERBANK & Kurumsal & KOBİ & Bireysel & Diğger & & \\
\hline T.EKONOMI & Bireysel & Kurumsal & KOBİ & Hazine Genel Müd. & & \\
\hline TEKSTILBANK & Bireysel & Kurumsal & Hazine / Yatırım & & & \\
\hline T.S.K.B. & Kurumsal & Yatırım & Diğer & & & \\
\hline T. VAKIFLAR & Bireysel & Kurumsal & Yatırım & Diğer & & \\
\hline YAPI VE KREDİ & Perakende & Kurumsal/Ticari & Özel & Hazine & & \\
\hline
\end{tabular}


Tablo 3 ve Tablo 4'deki veriler incelendiğinde göze çarpan en önemli husus, bölümsel raporlarda açıklanan finansal bilgi miktarlarının ve bölüm yapılarının farklılığıdır. Bu durum TFRS 8 standardındaki Yönetim Yaklaşımı (bu yaklaşımda standart şirketleri bölümsel raporları düzenlemede şekilsel olarak özgür bırakmıştır) ile, her bankanın farklı yönetim ve organizasyon yapılarından dolayı, kendine özgü bölümsel raporlar açıklama isteğiyle açıklanabilir. Ayrıca bazı bankalar sektörde yaşanan rekabet sebebiyle kısıtlı bölümsel raporlar düzenleyebilmektedir. Fakat bu durum bölümsel raporlardaki finansal bilgilerin karşılaştırılmasını ve analizini güçleştirmektedir. Böylece finansal tablo kullanıcıları, bankalar hakkında doğru yatırım ve yönetim kararları almakta zorlanabilmektedir.

Bankacılık sektörü kendine has işleyiş kuralları ve ticari yapısı olan özel yapıda bir sektördür. Bağımsız denetim raporları incelendiğinde Türkiye'de faaliyet gösteren bankaların birçoğunun benzer ticari faaliyetlerde bulunduğu görülebilmektedir. Bu sebeple bölümsel raporlarda açıklanan finansal bilgilerin içeriklerinin ve bölüm yapılarının bu denli farklı olmasının, gereklilikten çok yönetimsel bir karar olduğu görülebilmektedir.

Çalışmanın amacı, bankalardaki farklı bölümsel raporlama uygulamalarının tamamını kapsayan ortak bir bölümsel rapor uygulama önerisinde bulunmaktır. Uygulama çalışmasında bölümlerde açıklanan finansal bilgilerin ve faaliyet bölüm yapılarının detaylı olduğu bir örnek uygulama yapılması ve sektörde konu ile ilgili farkındalık yaratılması hedeflenmektedir.

\section{BÖLÜMSEL RAPOR UYGULAMASI}

Uygulama çalışması için öncelikle kurgulanan X bankasına ait, 31.12.20XX tarihli Finansal Durum Tablosu Tablo 5'deki şekliyle ve 01.01.20XX - 31.12.20XX dönemine ait Gelir Tablosu Tablo 6'daki şekliyle seçilen tesadüfi rakamlarla oluşturulmuştur.

Finansal Durum Tablosunda yer alan aktif ve pasifler Türk Lirası (TL) ve Yabancı Paralı (YP) olmak üzere iki farklı para birimi ile gösterilmiş olup, bölümsel raporlama uygulamasında "Toplam" sütunundaki değerler dikkate alınacaktır. 
Tablo 5: X Bankasının 31.12.20XX Tarihli Ait Konsolide Finansal Durum Tablosu

\begin{tabular}{|c|c|c|c|c|}
\hline & \multirow[t]{2}{*}{ AKTIF KALEMLER } & \multicolumn{3}{|c|}{ Cari Dönem (Bin TL) } \\
\hline & & TL & $\mathbf{Y P}$ & TOPLAM \\
\hline I. & NAKIT DEĞERLER VE MERKEZ BANKASI & 5.265 .768 & 18.143.973 & 23.409.741 \\
\hline II. & GERÇEĞE UYGUN DEĞ. FARKI KAR/ZAR. YAN. FV (Net) & 1.642 .222 & 1.293 .803 & 2.936 .025 \\
\hline 2.1 & Alm Satım Amaçh Finansal Varlklar & 1.642 .222 & 1.293 .803 & 2.936 .025 \\
\hline 2.1 .1 & Devlet Borçlanma Senetleri & 1.132 .898 & 5.901 & 1.138 .799 \\
\hline 2.1 .2 & Sermayede Payı Temsil Eden Menkul Değerler & 55.273 & 0 & 55.273 \\
\hline 2.1 .3 & Almm Satım Amaçh Türev Finansal Varlkklar & 40.316 & 1.248 .518 & 1.288 .834 \\
\hline 2.1 .4 & Diğer Menkul Değerler & 413.735 & 39.384 & 453.119 \\
\hline 2.2 & Gerçeğe Uygun Değer Farkı Kar/Zarara Yan. Olarak Simıflandırilan FV & 0 & 0 & \\
\hline 2.2 .1 & Devlet Borçlanma Senetleri & 0 & 0 & 0 \\
\hline 2.2 .2 & Sermayede Payı Temsil Eden Menkul Değerler & 0 & 0 & 0 \\
\hline 2.2 .3 & Krediler & 0 & 0 & \\
\hline 2.2 .4 & Diğer Menkul Değerler & 0 & 0 & \\
\hline III. & BANKALAR & 478.503 & 4.707.508 & 5.186 .011 \\
\hline IV. & PARA PIYYASALARINDAN ALACAKLAR & 140.375 & $\mathbf{0}$ & $\mathbf{1 4 0 . 3 7 5}$ \\
\hline 4.1 & Bankalararası Para Piyasalarmndan Alacaklar & 0 & 0 & 0 \\
\hline 4.2 & İMKB Takasbank Piyasasmdan Alacaklar & 128.447 & 0 & 128.447 \\
\hline 4.3 & Ters Repo İşlemlerinden Alacaklar & 11.928 & 0 & 11.928 \\
\hline V. & SATILMAYA HAZIR FINANSAL VARLIKLAR (Net) & 27.034 .185 & 7.241.218 & 34.275.403 \\
\hline 5.1 & Sermayede Payı Temsil Eden Menkul Değerler & 93.573 & 3.209 & 96.782 \\
\hline 5.2 & Devlet Borçlanma Senetleri & 26.162 .475 & 5.817 .614 & 31.980 .089 \\
\hline 5.3 & Diğer Menkul Değerler & 778.137 & 1.420 .395 & 2.198 .532 \\
\hline VI. & KREDİLER VE ALACAKLAR & 89.370.339 & 56.365 .932 & 145.736.271 \\
\hline 6.1 & Krediler ve Alacaklar & 88.862 .000 & 56.327 .919 & 145.189 .919 \\
\hline 6.1 .1 & Bankanm Dahil Olduğu Risk Grubuna Kullandırılan Krediler & 136.938 & 431.572 & 568.510 \\
\hline 6.1 .2 & Devlet Borçlanma Senetleri & 0 & 0 & \\
\hline 6.1 .3 & Diğer & 88.725 .062 & 55.896 .347 & 144.621 .409 \\
\hline 6.2 & Takipteki Krediler & 2.325 .180 & 151.153 & 2.476 .333 \\
\hline 6.3 & Özel Karşılkklar (-) & 1.816 .841 & 113.140 & 1.929 .981 \\
\hline VII. & VADEYE KADAR ELDE TUTULACAK YATIRIMLAR (Net) & 7.712 .750 & $\mathbf{1 5 . 6 9 7}$ & 7.728.447 \\
\hline 7.1 & Devlet Borçlanma Senetleri & 7.704 .816 & 0 & 7.704 .816 \\
\hline 7.2 & Diğer Menkul Değerler & 7.934 & 15.697 & 23.631 \\
\hline VIII. & ișTiRAKLER (Net) & 767.872 & 238 & 768.110 \\
\hline 8.1 & Özkaynak Yöntemine Göre Muhasebeleştirilenler & 96.644 & 0 & 96.644 \\
\hline 8.2 & Konsolide Edilmeyenler & 671.228 & 238 & 671.466 \\
\hline 8.2 .1 & Mali İștirakler & 0 & 0 & \\
\hline 8.2 .2 & Mali Olmayan İștirakler & 671.228 & 238 & 671.466 \\
\hline IX. & BAĞLI ORTAKLIKLAR (Net) & 3.406 .441 & $\mathbf{0}$ & 3.406.441 \\
\hline 9.1 & Konsolide Edilmeyen Mali Ortakliklar & 0 & 0 & \\
\hline 9.2 & Konsolide Edilmeyen Mali Olmayan Ortaklklar & 3.406 .441 & 0 & 3.406 .441 \\
\hline $\mathbf{X .}$ & BİRLIKTE KONTROL EDILEN ORT. (ISS ORT.)(Net) & $\mathbf{0}$ & $\mathbf{0}$ & \\
\hline 10.1 & Özkaynak Yöntemine Göre Muhasebeleștirilenler & 0 & 0 & 0 \\
\hline 10.2 & Konsolide Edilmeyenler & 0 & 0 & 0 \\
\hline 10.2 .1 & Mali Ortaklkklar & 0 & 0 & 0 \\
\hline 10.2 .2 & Mali Olmayan Ortaklkklar & 0 & 0 & 0 \\
\hline XI. & KIRALAMA ISSLEMLERINNDEN ALACAKLAR & 470.502 & 1.563 .620 & 2.034 .122 \\
\hline 11.1 & Finansal Kiralama Alacakları & 551.498 & 1.775 .923 & 2.327 .421 \\
\hline 11.2 & Faaliyet Kiralaması Alacakları & 757 & 0 & 757 \\
\hline 11.3 & Diğer & 0 & 0 & 0 \\
\hline 11.4 & Kazanılmamış Gelirler ( - ) & 81.753 & 212.303 & 294.056 \\
\hline XII. & RISKTEN KORUNMA AMAÇLI TÜREV FİN. VARLIKLAR & $\mathbf{0}$ & $\mathbf{0}$ & \\
\hline 12.1 & Gerçeğe Uygun Değer Riskinden Korunma Amaçllar & 0 & 0 & 0 \\
\hline 12.2 & Nakit Akış Riskinden Korunma Amaçllar & 0 & 0 & 0 \\
\hline 12.3 & Yurtdışmdaki Net Yatrrm Riskinden Korunma Amaçllar & 0 & 0 & 0 \\
\hline XIII. & MADDİ DURAN VARLIKLAR (Net) & 2.137 .896 & 96.432 & 2.234 .328 \\
\hline XIV. & MADDİ OLMAYAN DURAN VARLIKLAR (Net) & 288.050 & 4.967 & 293.017 \\
\hline 14.1 & Şerefiye & 35.974 & 0 & 35.974 \\
\hline 14.2 & Diğer & 252.076 & 4.967 & 257.043 \\
\hline XV. & YATIRIM AMAÇLI GAYRIMENKULLER (Net) & 1.342 .182 & $\mathbf{0}$ & 1.342 .182 \\
\hline XVI. & VERGİ VARLIĞI & 676.790 & $\mathbf{1 5 . 9 7 4}$ & 692.764 \\
\hline 16.1 & Cari Vergi Varlı̆ı & 18.785 & 7.436 & 26.221 \\
\hline 16.2 & Ertelenmiş Vergi Varlığı & 658.005 & 8.538 & 666.543 \\
\hline XVII. & SATIŞ AMAÇ. EL.TUT. VE DUR.FAAL.İLiŞ.DUR.VAR. (Net) & 65.777 & 2.872 & 68.649 \\
\hline 17.1 & Satıs Amaçh & 65.777 & 2.872 & 68.649 \\
\hline 17.2 & Durdurulan Faaliyetlere İlişkin & 0 & 0 & 0 \\
\hline XVIII. & DİĞER AKTIFLER & 9.425 .060 & 1.936 .240 & 11.361 .300 \\
\hline & AKTIF TOPLAMI & 150.224.712 & 91.388.474 & 241.613.186 \\
\hline
\end{tabular}




\begin{tabular}{|c|c|c|c|c|}
\hline & \multirow[t]{2}{*}{ PASİF KALEMLER } & \multicolumn{3}{|c|}{ Cari Dönem (Bin TL) } \\
\hline & & $\mathbf{T L}$ & $\mathbf{Y P}$ & TOPLAM \\
\hline I. & MEVDUAT & 65.359.750 & 56.478 .048 & 121.837.798 \\
\hline 1.1 & Bankanın Dahil Olduğu Risk Grubunun Mevduatı & 892.591 & 1.476 .460 & 2.369 .051 \\
\hline 1.2 & Diğer & 64.467 .159 & 55.001 .588 & 119.468 .747 \\
\hline II. & ALIM SATIM AMAÇLI TÜREV FINANSAL BORÇLAR & 696.001 & 501.344 & $\mathbf{1 . 1 9 7 . 3 4 5}$ \\
\hline III. & ALINAN KREDİLER & 3.111 .333 & 24.112 .363 & 27.223 .696 \\
\hline IV. & PARA PİYASALARINA BORÇLAR & 20.823.398 & 4.176.477 & 24.999.875 \\
\hline 4.1 & Bankalararası Para Piyasalarına Borçlar & 0 & 0 & 0 \\
\hline 4.2 & İMKB Takasbank Piyasasına Borçlar & 2.403 .976 & 0 & 2.403 .976 \\
\hline 4.3 & Repo İşlemlerinden Sağlanan Fonlar & 18.419 .422 & 4.176 .477 & 22.595 .899 \\
\hline V. & İHRAÇ EDİLEN MENKUL KIYMETLER (Net) & 5.134 .330 & 4.942 .514 & 10.076 .844 \\
\hline 5.1 & Bonolar & 3.896 .072 & 158.658 & 4.054 .730 \\
\hline 5.2 & Varlığa Dayalı Menkul Kıymetler & 0 & 0 & 0 \\
\hline 5.3 & Tahviller & 1.238 .258 & 4.783 .856 & 6.022 .114 \\
\hline VI. & MUHTELIF BORÇLAR & 10.448.283 & 701.857 & $\mathbf{1 1 . 1 5 0 . 1 4 0}$ \\
\hline VII. & DİĞER YABANCI KAYNAKLAR & 1.508.917 & 3.308 .205 & 4.817.122 \\
\hline VIII. & KİRALAMA İŞLEMLERİNDEN BORÇLAR & $\mathbf{0}$ & $\mathbf{0}$ & $\mathbf{0}$ \\
\hline 8.1 & Finansal Kiralama Borçları & 0 & 0 & 0 \\
\hline 8.2 & Faaliyet Kiralaması Borçları & 0 & 0 & 0 \\
\hline 8.3 & Diğer & 0 & 0 & 0 \\
\hline 8.4 & Ertelenmiş Finansal Kiralama Giderleri (-) & 0 & 0 & 0 \\
\hline IX. & RİSKTEN KORUNMA AMAç. TÜREV FİN. BORÇLAR & $\mathbf{0}$ & $\mathbf{0}$ & $\mathbf{0}$ \\
\hline 9.1 & Gerçeğe Uygun Değer Riskinden Korunma Amaçlilar & 0 & 0 & 0 \\
\hline 9.2 & Nakit Akış Riskinden Korunma Amaçlilar & 0 & 0 & 0 \\
\hline 9.3 & Yurtdışındaki Net Yatırım Riskinden Korunma Amaçlılar & 0 & 0 & 0 \\
\hline $\mathbf{X}$ & KARŞILIKLAR & 10.094.287 & 824.681 & 10.918 .968 \\
\hline 10.1 & Genel Karşllklar & 2.073 .263 & 27.339 & 2.100 .602 \\
\hline 10.2 & Yeniden Yapılanma Karşıllğı & 0 & 0 & 0 \\
\hline 10.3 & Çalışan Hakları Karşılığı & 411.438 & 2.058 & 413.496 \\
\hline 10.4 & Sigorta Teknik Karşılkkları (Net) & 4.029 .494 & 771.746 & 4.801 .240 \\
\hline 10.5 & Diğer Karşılıklar & 3.580 .092 & 23.538 & 3.603 .630 \\
\hline XI. & VER Gİ BORCU & 402.334 & 3.536 & 405.870 \\
\hline 11.1 & Cari Vergi Borcu & 399.735 & 3.536 & 403.271 \\
\hline 11.2 & Ertelenmiş Vergi Borcu & 2.599 & 0 & 2.599 \\
\hline XII. & $\begin{array}{l}\text { SATIŞ AMAÇLI ELDE TUTULAN VE DURDURULAN } \\
\text { FAAL. İLİŞKIN DURAN VARLIK BORÇLARI (Net) }\end{array}$ & $\mathbf{0}$ & $\mathbf{0}$ & $\mathbf{0}$ \\
\hline 12.1 & Satış Amaçlı & 0 & 0 & 0 \\
\hline 12.2 & Durdurulan Faaliyetlere İlişkin & 0 & 0 & 0 \\
\hline XIII. & SERMAYE BENZERİ KREDİLER & $\mathbf{0}$ & 3.090 .902 & 3.090 .902 \\
\hline XIV. & ÖZKAYNAK LAR & 25.809 .518 & 85.108 & 25.894 .626 \\
\hline 14.1 & Ödenmiş Sermaye & 4.500 .000 & 0 & 4.500 .000 \\
\hline 14.2 & Sermaye Yedekleri & 2.360 .886 & -31.790 & 2.329 .096 \\
\hline 14.2.1 & Hisse Senedi İhraç Primleri & 33.940 & 0 & 33.940 \\
\hline 14.2 .2 & Hisse Senedi İptal Kârları & 0 & 0 & 0 \\
\hline 14.2 .3 & Menkul Değerler Değerleme Farkları & 712.187 & -31.790 & 680.397 \\
\hline 14.2 .4 & Maddi Duran Varlkklar Yeniden Değerleme Farkları & 0 & 0 & 0 \\
\hline 14.2 .5 & Maddi Olmayan Duran Varlıklar Yeniden Değerleme Farkları & 0 & 0 & 0 \\
\hline 14.2 .6 & Yatırım Amaçlı Gayrimenkuller Yeniden Değerleme Farkları & 0 & 0 & 0 \\
\hline 14.2 .7 & İştirakler, Bağlı Ort. ve Bir. Kont. Ed. Ort. (İş Ort) Bed. Hisse Sen. & -1.179 & 0 & -1.179 \\
\hline 14.2 .8 & Riskten Korunma Fonları (Etkin Kısım) & 0 & 0 & 0 \\
\hline 14.2 .9 & Satış Amaçlı Elde Tut. ve Dur. Faal. Duran Var. Bir. Değ. Farkları & 0 & 0 & 0 \\
\hline 14.2.10 & Diğer Sermaye Yedekleri & 1.615 .938 & 0 & 1.615 .938 \\
\hline 14.3 & Kâr Yedekleri & 13.153 .484 & 157.434 & 13.310 .918 \\
\hline 14.3.1 & Yasal Yedekler & 2.286 .486 & 0 & 2.286 .486 \\
\hline 14.3 .2 & Statü Yedekleri & 59.539 & 0 & 59.539 \\
\hline 14.3 .3 & Olağanüstü Yedekler & 10.792 .384 & 20.360 & 10.812 .744 \\
\hline 14.3 .4 & Diğer Kâr Yedekleri & 15.075 & 137.074 & 152.149 \\
\hline 14.4 & Kâr veya Zarar & 2.672 .230 & -51.068 & 2.621 .162 \\
\hline 14.4 .1 & Geçmiş Yıllar Kâr/Zararı & -621.726 & 6.967 & -614.759 \\
\hline 14.4 .2 & Dönem Net Kâr/Zararı & 3.293 .956 & -58.035 & 3.235 .921 \\
\hline 14.5 & Azınlık Payları & 3.122 .918 & 10.532 & 3.133 .450 \\
\hline & PASİF TOPLAMI & 143.388.151 & 98.225.035 & 241.613 .186 \\
\hline
\end{tabular}


Tablo 6: X Bankasının 01.01.20XX-31.12.20XX Dönemine Ait Konsolide Gelir Tablosu

\begin{tabular}{|c|c|c|}
\hline & (BI) \\
\hline & & TUTAR \\
\hline I. & FAİZ GELİRLERİ & 14.853 .908 \\
\hline 1.1 & Kredilerden Alman Faizler & 10.879 .785 \\
\hline 1.2 & Zorunlu Karşılıklardan Alınan Faizler & 0 \\
\hline 1.3 & Bankalardan Alınan Faizler & 162.261 \\
\hline 1.4 & Para Piyasası İşlemlerinden Alınan Faizler & 14.374 \\
\hline 1.5 & Menkul Değerlerden Alınan Faizler & 3.570 .864 \\
\hline 1.5 .1 & Alım Satım Amaçlı Finansal Varlıklardan & 55.878 \\
\hline 1.5 .2 & Gerçeğe Uygun Değer Farkı Kar/Zarara Yans. Olarak Sınıf. FV & 0 \\
\hline 1.5 .3 & Satılmaya Hazır Finansal Varlıklardan & 2.277 .936 \\
\hline 1.5 .4 & Vadeye Kadar Elde Tutulacak Yatırımlardan & 1.237 .050 \\
\hline 1.6 & Finansal Kiralama Gelirleri & 126.046 \\
\hline 1.7 & Diğer Faiz Gelirleri & 100.578 \\
\hline II. & FAİZ GİDERLERİ & 7.172 .014 \\
\hline 2.1 & Mevduata Verilen Faizler & 4.797 .189 \\
\hline 2.2 & Kullanılan Kredilere Verilen Faizler & 528.881 \\
\hline 2.3 & Para Piyasası İşlemlerine Verilen Faizler & 1.165 .751 \\
\hline 2.4 & İhraç Edilen Menkul Krymetlere Verilen Faizler & 595.555 \\
\hline 2.5 & Diğer Faiz Giderleri & 84.638 \\
\hline III. & NET FAİZ GELİRİ/GİDERİ (I - II) & 7.681 .894 \\
\hline IV. & NET ÜCRET VE KOMİSYON GELİRLERİ/GİDERLERİ & 1.468.946 \\
\hline 4.1 & Alman Ücret ve Komisyonlar & 2.400 .210 \\
\hline 4.1 .1 & Gayri Nakdi Kredilerden & 236.835 \\
\hline 4.1 .2 & Diğer & 2.163 .375 \\
\hline 4.2 & Verilen Ücret ve Komisyonlar & 931.264 \\
\hline 4.2 .1 & Gayri Nakdi Kredilere & 8.659 \\
\hline 4.2 .2 & Diğer & 922.605 \\
\hline V. & TEMETTÜ GELİRLERİ & 238.057 \\
\hline VI. & TÍCARİ KÂR / ZARAR (Net) & 378.591 \\
\hline 6.1 & Sermaye Piyasası İşlemleri Kârı/Zararı & 181.749 \\
\hline 6.2 & Türev Finansal İşlemlerden Kâr/Zarar & -500.764 \\
\hline 6.3 & Kambiyo İșlemleri Kârı/Zararı & 697.606 \\
\hline VII. & DİĞER FAALIYYET GELİRLERİ & 4.615.411 \\
\hline VIII. & FAALIYYET GELİRLERİ/GID. TOPLAMI (III+IV+V+VI+VII) & 14.382.899 \\
\hline IX. & KREDİ VE DİĞER ALACAKLAR DEĞER DÜŞÜŞ KARŞ. (-) & $\mathbf{1 . 6 5 4 . 7 0 1}$ \\
\hline $\mathbf{X}$ & DİĞER FAALİYET GİDERLERİ (-) & 8.308.239 \\
\hline XI. & NET FAALİYET KÂRI/ZARARI (VIII-IX-X) & 4.419.959 \\
\hline XII. & BİRLEŞME İŞL. SON. GELİR OL. KAYD. FAZ. TUTAR & $\mathbf{0}$ \\
\hline XIII. & ÖZKAYNAK YÖNTEMİ UYGULANAN ORT. KÂR/ZARAR & 9.922 \\
\hline XIV. & NET PARASAL POZISYYN KÂRI/ZARARI & $\mathbf{0}$ \\
\hline XV. & SÜRDÜRÜLEN FAAL. VERGİ ÖNCESİ K/Z (XI+...+XIV) & 4.429.881 \\
\hline XVI. & SÜRDÜRÜLEN FAAL. VER Gİ KARŞILIĞI ( $( \pm)$ & 823.022 \\
\hline 16.1 & Cari Vergi Karşıı̆ğı & 472.907 \\
\hline 16.2 & Ertelenmiş Vergi Karşılığ & 350.115 \\
\hline XVII. & SÜRDÜRÜLEN FAAL. DÖNEM NET K/Z (XV \pm XVI) & 3.606.859 \\
\hline XVIII. & DURDURULAN FAALİYETLERDEN GELİRLER & $\mathbf{0}$ \\
\hline 18.1 & Satış Amaçlı Elde Tutulan Duran Varlık Gelirleri & 0 \\
\hline 18.2 & İştirak, Bağlı Ortaklık ve Bir. Kont. Ed. Ort. (İş. Ort.) Satış Karları & 0 \\
\hline 18.3 & Diğer Durdurulan Faaliyet Gelirleri & 0 \\
\hline XIX. & DURDURULAN FAALİYETLERDEN GİDERLER (-) & $\mathbf{0}$ \\
\hline 19.1 & Satış Amaçlı Elde Tutulan Duran Varlık Giderleri & 0 \\
\hline 19.2 & İştirak, Bağlı Ortaklık ve Birlikte Kont. Edilen Ort. (İş Ort.) Satış Zar. & 0 \\
\hline 19.3 & Diğer Durdurulan Faaliyet Giderleri & 0 \\
\hline $\mathbf{X X}$. & DURDURULAN FAAL. VERGİ ÖNCESİ K/Z (XVIII-XIX) & $\mathbf{0}$ \\
\hline XXI. & DURDURULAN FAAL. VER Gİ KARȘILIĞI ( $( \pm)$ & $\mathbf{0}$ \\
\hline 21.1 & Cari Vergi Karşılığ & 0 \\
\hline 21.2 & Ertelenmiş Vergi Gider Karşıllığ & 0 \\
\hline XXII. & DURDURULAN FAAL. DÖNEM NET K/Z (XX土XXI) & $\mathbf{0}$ \\
\hline XXIII. & NET DÖNEM KARI/ZARARI (XVII+XXII) & 3.606.859 \\
\hline 23.1 & Grubun Kârı / Zararı & 3.235 .921 \\
\hline 23.2 & Azınlık Payları Kârı / Zararı (-) & 370.938 \\
\hline & Hisse Başına Kâr / Zarar & 1 \\
\hline
\end{tabular}




\begin{abstract}
Uygulama çalışmasının amacı, bankalardaki farklı bölümsel raporlama uygulamalarının tamamını kapsayan ortak bir bölümsel rapor uygulama önerisinde bulunmaktır. Bu amaçla çalışmaya konu tüm bankaların faaliyet bölüm yapıları incelenmiş ve Tablo 7'de görüldüğü üzere örnek X bankasının "Kurumsal”, "Ticari”, "Bireysel” ve Hazine / Yatırım" olmak üzere dört bölümde faaliyet gösterdiği öngörülmüştür. Ayrıca faaliyet bölümlendirmesi yapılamayacak kalem ve miktarlar için bir "Dağıtılamayan” bölümü oluşturulmuştur.
\end{abstract}

Faaliyet bölümlendirmesinde bölümlendirmeye konu olacak finansal tablo bilgilerinin seçiminde iki faktör dikkate alınmıştır. Birincisi çalışmaya konu olan tüm bankaların faaliyet bölümleri incelenmiş ve detaylı bölümsel raporlar örnek alınarak ortak noktalar tespit edilmiştir. İkinci olarak bölümsel rapor bilgilerini kullanacak ilgili tarafların detaylı bilgi alabilmeleri öngörülmüş ve önemli görülen finansal tablo kalemlerinin bölümsel raporlamada yer alması gerekliliği dikkate alınmıştır. Böylece uygulama önerisinde tüm bankaları kapsayabilecek detaylı bir örnek bölümsel raporlama çalışması yapılması hedeflenmiştir.

X bankasının 01.01.20XX - 31.12.20XX dönemine ait faaliyet bölümlendirmesi Tablo 7'de verilmiştir. Tablo iki bölümden oluşmaktadır. Birinci bölümde gelir tablosu ile ilgili bölümsel bilgilere, ikinci bölümde ise finansal durum tablosu ile ilgili bölümsel bilgilere yer verilmiştir. Bölümlendirme yapılmayan miktar ve kalemler için "Dağıtılamayan” sütunu kullanılmıştır. Ayrıca finansal durum tablosu verilerinin bölümlendirme işlemlerinde varlık ve yükümlülük toplamlarında eşitlik sağlamak amacıyla, bölümlendirilemeyen varlık ve yükümlülükler “Diğer” başlık kaleminde toplanmıştır.

Finansal bilgilerin bölümlendirmesinde ilgili finansal kalemin, hangi faaliyet bölümü ile hangi oranda ilgili olabileceği, bankaların geçmiş dönem bölümsel raporlarının detaylı olarak incelenmesi sonucu tespit edilmiştir. Sonrasında ilgili finansal kalemin bölümlendirmesi, oransal fakat tesadüfi rakamlar üzerinden gerçekleştirilmiştir.

Bölümsel raporlamada yer verilen bilgilerin, ilgili finansal tablodaki yerini gösterebilmek ve takibi kolaylaştırmak amaciyla tabloya "NOT" sütunu ilave edilmiş ve başlık numaraları bu sütuna yazılmıştır. 
Tablo 7: X Bankasının 01.01.20XX-31.12.20XX Dönemine Ait Faaliyet Bölümlendirme Tablosu

(Bin TL.)

\begin{tabular}{|c|c|c|c|c|c|c|c|}
\hline \multirow[b]{2}{*}{ GELİR TABLOSU BİLGİLERİ } & \multicolumn{7}{|c|}{ CARİ DÖNEM (Bin TL) } \\
\hline & NOT & Kurumsal & Ticari & Bireysel & Hazine / Yatırm & Dağttlamayan & TOPLAM \\
\hline FAİZ GELİRLERİ & I. & 2.380 .559 & 4.529 .831 & 3.723 .543 & 3.733 .125 & 486.850 & 14.853 .908 \\
\hline Kredilerden Alnnan Faizler & 1.1 & 2.380 .559 & 4.529 .831 & 3.723 .543 & & 245.852 & 10.879 .785 \\
\hline Bankalardan Alnan Faizler & 1.3 & & & & 162.261 & & 162.261 \\
\hline Para Piyasası İşlemlerinden Alman Faizler & 1.4 & & & & & 14.375 & 14.374 \\
\hline Menkul Değerlerden Alnan Faizler & 1.5 & & & - & 3.570 .864 & & 3.570 .864 \\
\hline Finansal Kiralama Gelirleri & 1.6 & & & & & 126.046 & 126.046 \\
\hline Diğer Faiz Gelirleri & 1.7 & & & & & 100.578 & 100.578 \\
\hline FAİZ GIDERLERİ (-) & II. & $(933.631)$ & $(724.155)$ & (2.873.395) & $(2.290 .187)$ & $(350.646)$ & $(7.172 .014)$ \\
\hline Mevduata Verilen Faizler (-) & 2.1 & $(933.631)$ & $(724.155)$ & $(2.873 .395)$ & & $(266.008)$ & (4.797.189) \\
\hline Kullanilan Kredilere Verilen Faizler (-) & 2.2 & & & & (528.881) & & (528.881) \\
\hline Para Piyasası İșlemlerine Verilen Faizler (-) & 2.3 & & & - & $(1.165 .751)$ & & $(1.165 .751)$ \\
\hline İhraç Edilen Menkul Krymetlere Verilen Faizler (-) & 2.4 & & & - & (595.555) & & $(595.555)$ \\
\hline Diğer Faiz Giderleri (-) & 2.5 & & & & & (84.638) & (84.638) \\
\hline NET FAİZ GELİRİ/GİDERİ (I + II) & III. & 1.446 .928 & 3.805 .676 & 850.148 & 1.442 .938 & 136.204 & 7.681 .894 \\
\hline NET ÜCRET VE KOM. GELİRLERİ/GIDERLERİ & IV. & 381.772 & 966.744 & 965.311 & $(931.264)$ & 86.383 & 1.468 .946 \\
\hline Alman Ücret ve Komisyonlar & 4.1 & 381.772 & 966.744 & 965.311 & & 86.383 & 2.400 .210 \\
\hline Verilen Ücret ve Komisyonlar (-) & 4.2 & & & & $(931.264)$ & & $(931.264)$ \\
\hline TEMETTÜ GELİRLERI & $\mathrm{V}$. & & & & 238.057 & & 238.057 \\
\hline TÍCARİ KÂR / ZARAR (Net) & VI. & & & & 378.591 & & 378.591 \\
\hline Sermaye Piyasası İşlemleri Kâr/Zararı & 6.1 & & & & 181.749 & & 181.749 \\
\hline Türev Finansal İşlemlerden Kâr/Zarar & 6.2 & & & & $(500.764)$ & & $(500.764)$ \\
\hline Kambiyo İșlemleri KârıZZararı & 6.3 & & & & 697.606 & & 697.606 \\
\hline DİĞER FAALIYYT GELİRLERİ & VII. & 129.899 & 1.532 .476 & 1.318 .649 & 1.453 .913 & 180.474 & 4.615 .411 \\
\hline KREDİ VE DİĞER ALAC. DEĞ. DÜŞÜŞ KARŞ.(-) & IX. & $(136.879)$ & $(860.619)$ & (598.209) & (26.721) & $(32.273)$ & $(1.654 .701)$ \\
\hline DIĞER FAALIYET GIDERLERİ (-) & $\mathrm{X}$. & $(711.928)$ & (2.914.927) & (3.453.675) & $(1.097 .334)$ & $(130.375)$ & $(8.308 .239)$ \\
\hline SÜRDÜRÜLEN FAAL. VERGI ÖNCESİ K/Z & $\mathrm{XV}$. & 815.600 & 1.414 .600 & 1.514 .515 & 616.400 & 68.766 & 4.429 .881 \\
\hline SÜRDÜRÜLEN FAAL. VERGİ KAR ŞILIĞI ( $( \pm)$ & XVI. & & & & & $(823.022)$ & $(823.022)$ \\
\hline NET DÖNEM KARI/ZARARI & XXIII. & 815.600 & 1.414 .600 & 1.514 .515 & 616.400 & $(754.256)$ & 3.606 .859 \\
\hline
\end{tabular}

\section{FİNANSAL DURUM TABLOSU BILGIILERİ}

\begin{tabular}{|c|c|c|c|c|c|c|c|}
\hline BÖLÜM VARLIKLARI & & & & & & & 241.613 .186 \\
\hline NAKİT DEĞERLER VE MERKEZ BANKASI & I. & - & & & 23.409 .741 & & 23.409 .741 \\
\hline GERÇ. UYG.DEĞ. FARKI KAR/ZAR.YAN.FV (Net) & II. & - & & - & 2.936 .025 & & 2.936.025 \\
\hline BANKALAR & III. & - & - & - & 5.186 .011 & & 5.186 .011 \\
\hline PARA PIYASALARINDAN ALACAKLAR & IV. & - & & - & 140.375 & & 140.375 \\
\hline SATILMAYA HAZIR FINANSAL VARLIKLAR (Net) & V. & - & & & 34.275 .403 & & 34.275 .403 \\
\hline KREDILER VE ALACAKLAR & VI. & 44.568 .109 & 62.151 .330 & 38.404 .513 & - & 612.319 & 145.736 .271 \\
\hline VADEYE KADAR ELDE TUTULACAK YAT. (Net) & VII. & - & & & 7.728 .447 & & 7.728 .447 \\
\hline İSTIRAKLER (Net) & VIII. & - & - & - & 768.110 & - & 768.110 \\
\hline BAĞLI ORTAKLIKLAR (Net) & IX. & - & - & - & 3.406 .441 & - & 3.406 .441 \\
\hline KİRALAMA İŞLEMLERİNDEN ALACAKLAR & XI. & - & 2.034 .122 & - & - & & 2.034 .122 \\
\hline DIĞĞER & & & & & & 15.992 .240 & 15.992 .240 \\
\hline
\end{tabular}

\begin{tabular}{|c|c|c|c|c|c|c|c|}
\hline BÖLÜM YÜKÜMLÜLÜKLERI & & & & & & & 241.613.186 \\
\hline MEVDUAT & I. & 18.489 .358 & 33.280 .601 & 67.392 .329 & - & 2.675 .510 & 121.837.798 \\
\hline ALIM SATIM AMAÇLI TÜREV FİN. BORÇLAR & II. & - & & & 1.197 .345 & & 1.197 .345 \\
\hline ALINAN KREDİLER & III. & - & & & 27.223 .696 & & 27.223 .696 \\
\hline PARA PIYASALARINA BORÇLAR & IV. & - & - & - & 24.999 .875 & & 24.999 .875 \\
\hline İHRAÇ EDILEEN MENKUL KIYMETLER (Net) & $\mathrm{V}$. & - & - & - & 10.076 .844 & 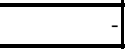 & 10.076 .844 \\
\hline MUHTELIF BORÇLAR & VI. & 3.415 .212 & 2.514 .618 & 4.912 .532 & & 307.778 & 11.150 .140 \\
\hline KARŞILIKLAR & $\mathrm{X}$. & - & & & 10.918 .968 & & 10.918 .968 \\
\hline DİĞER & XIV. & - & - & - & & 34.208 .520 & 34.208 .520 \\
\hline
\end{tabular}




\section{SONUÇ VE ÖNERİLER}

Dünya ticaret hacminin büyümesi ile beraber birden çok alanda faaliyet göstermeye başlayan şirketlerde, konsolide edilen finansal tablolardan elde edilen finansal bilgiler, kullanıcılara detayları gösterme konusunda yetersiz kalmaya başlamıştır. Bunun yanında sermaye piyasalarının yaygınlaşması kurumsal ve bireysel yatırımcıların sayısını arttırmıştır. Sermaye piyasalarındaki artan rekabet nitelikli ve detaylı finansal bilgi ihtiyacını da beraberinde getirmiştir. Bu sebeplerle son zamanlarda önemini arttıran bölümsel raporlama faaliyetleri Türkiye'de TFRS 8 standardı şartları doğrultusunda uygulanmaktadır.

TFRS 8 standardı bölümsel raporlamada bir şablon önermemekte, şirketleri bölüm yapılarını oluşturmada ve bölümlendirilecek finansal bilgilerin seçiminde serbest bırakmaktadır. Bu durum standardın temelini oluşturan "Yönetim Yaklaşımı"nın bir sonucudur.

Türkiye'de bankacılık sektörü, kendine has işleyiş kuralları ile benzer ticari faaliyetlerin gerçekleştirildiği bir sektördür. Fakat sektördeki bölümsel raporlama uygulamalarında, yukarıda belirtilen sebeplerden dolayı bir uygulama birliği sağlanamamıştır. Hatta bazı bankalar sektörde yaşanan yoğun rekabet sebebiyle, çok kısıtlı finansal bilgiler içeren bölümsel raporlar düzenleyebilmektedir. Bu durum bölümsel raporlardaki finansal bilgilerin karşılaştırılmasını ve analizini güçleştirmektedir.

Yapılan uygulama çalışması ile, bankalardaki farklı bölümsel raporlama uygulamalarını ortak bir paydada birleştiren, bir bölümsel raporlama önerisi ortaya konulmuştur. Böylece sektörde konunun tartışmaya açılarak, bölümsel raporlamada temelde bir uygulama birliği sağlanması hususunda farkındalık yaratılması hedeflenmiştir. TFRS 8 standardının önerdiği bir bölümsel raporlama şablonu bulunmasa bile, bu tip sektörlerde uygulama birliğinin sağlanmasında bir engel bulunmamaktadır. Fakat konu ile ilgili nihai karar şirket yönetimlerine kalmaktadır.

\section{KAYNAKLAR}

Benlamin, S. Jebaraj - Muthaiyah, Saravanan - Marathamuthu, M Srikamaladevi. Murugaiah, Uthiyakumar (2010), “A Study of Segment Reporting Practices: A Malasian Perspective”, A Journal of Applied Business Research, Vol.26, Issue.3, pp. 31-41.

Birt, Jacqueline - Kend, Mike - Xian, Hui (2007), “Changes In Segment Reporting In The Australian Banking Industry”, Australian Accounting Review, Vol. 17, Issue 3, pp. 61-67.

Elitaş, Cemal - Özdemir, Serkan - Karakoç, Mehtap (2012), "TFRS 8 Faaliyet Bölümleri Standard1 İle Bankalardaki Bölümsel Raporlama Uygulamalarında Gerçekleşen Değişimler: İMKB Uygulaması", ISAF 2012, 1. Uluslararası Muhasebe ve Finans Sempozyumu, 31 Mayıs - 2 Haziran, Gaziantep, ss. 123-134

http://www.kap.gov.tr/ , 27.11.2014. 
Link, Kewin W. (2003), "Segment Reporting: Analysis of the Impact on the Banking Industry”, The Journal of Bank Cost \& Management Accounting, Vol. 16, Issue 3, pp. 34-40.

TFRS 8 Faaliyet Bölümleri Standard1, http://kgk.gov.tr/contents/files/TFRS-8.pdf (27.11.2014). 